\title{
Votation générale de FMH Services 2010
}

\section{Max Giger ${ }^{a}$, Reinhard Kunz ${ }^{b}$ \\ a Dr, Président du Conseil d'administration \\ b Directeur de FMH Services}

Chères associées, chers associés,

Par le biais de notre rapport de gestion 2009, nous vous avons informé de nos activités opérationnelles et des succès obtenus. Nous vous avons demandé simultanément d'approuver ce rapport et de donner décharge au Conseil d'administration. Aujourd'hui, nous avons le plaisir de vous informer des résultats de la votation générale. Nous vous remercions de votre intérêt et de la confiance que vous témoignez à l'égard de FMH Services.

\section{Résultats de la votation générale 2010}

\section{Organe de publication}

Bulletin des médecins suisses $n^{\circ}$ 28/29 du 14 juillet 2010.

\section{Remise des bulletins de vote}

Du 12 mai au 12 juin 2010 auprès de la commune d'Oberkirch.

\section{Dépouillement}

M. J. R. Rogger, commune d'Oberkirch.

\section{Propositions}

1. Approbation du rapport de gestion 2009

2. Affectation du bénéfice 2009

3. Décharge au Conseil d'administration

4. Election de l'organe de révision

5. Election de l'instance tierce neutre pour le déroulement des votations générales

\section{Résultats}

\subsection{Proposition $\mathrm{n}^{\circ} 1$}

Acceptez-vous le rapport de gestion 2009 de FMH Services?

$\begin{array}{lr}\text { Bulletins de vote reçus } & 1277 \\ \text { Bulletins invalides } & 147 \\ \text { Bulletins vides } & 21 \\ \text { Bulletins valables } & 1109 \\ \text { Oui } & 1090 \\ \text { Non } & 19\end{array}$

La proposition $n^{\circ} 1$ est ainsi approuvée à une large majorité.

\subsection{Proposition $\mathrm{n}^{\circ} 2$}

Etes-vous d'accord de reporter le bénéfice de 467298 francs sur l'exercice suivant et de l'attribuer aux réserves générales?

$\begin{array}{lr}\text { Bulletins de vote reçus } & 1278 \\ \text { Bulletins invalides } & 147 \\ \text { Bulletins vides } & 20 \\ \text { Bulletins valables } & 1111 \\ \text { Oui } & 1084 \\ \text { Non } & 27\end{array}$

La proposition $n^{\circ} 2$ est ainsi approuvée à une large majorité.

\subsection{Proposition 3}

Etes-vous d'accord de donner décharge au conseil d'administration de FMH Services selon la recommandation de l'organe de révision?

$\begin{array}{lr}\text { Bulletins de vote reçus } & 1278 \\ \text { Bulletins invalides } & 147 \\ \text { Bulletins vides } & 23 \\ \text { Bulletins valables } & 1108 \\ \text { Oui } & 1093 \\ \text { Non } & 15\end{array}$

La proposition $\mathrm{n}^{\circ} 3$ est ainsi approuvée à une large majorité.

\subsection{Proposition $n^{\circ} 4$}

Acceptez-vous de nommer comme organe de révision pour un nouveau mandat d'un an la firme Truvag Revisions SA à Sursee?

$\begin{array}{lr}\text { Bulletins de vote reçus } & 1276 \\ \text { Bulletins invalides } & 147 \\ \text { Bulletins vides } & 34 \\ \text { Bulletins valables } & 1095 \\ \text { Oui } & 1076 \\ \text { Non } & 19\end{array}$

La proposition $\mathrm{n}^{\circ} 4$ est ainsi approuvée à une large majorité.

\subsection{Proposition $\mathrm{n}^{\circ} 5$}

Acceptez-vous de nommer, pour un nouveau mandat d'un an, l'administration communale d'Oberkirch comme instance tierce neutre pour l'exécution des votations générales?

$\begin{array}{lr}\text { Bulletins de vote reçus } & 1276 \\ \text { Bulletins invalides } & 147 \\ \text { Bulletins vides } & 29 \\ \text { Bulletins valables } & 1100 \\ \text { Oui } & 1085 \\ \text { Non } & 15\end{array}$

La proposition $\mathrm{n}^{\circ} 5$ est ainsi approuvée à une large majorité.

Le résultat de cette votation générale a été confirmé le 16 juin 2010 par J. R. Rogger, c/o administration communale d'Oberkirch, comme étant correct et exhaustif. 